\title{
Changing efficiency of BRICS currency markets during the COVID-19 pandemic
}

\author{
Andrew Phiri ${ }^{1}$
}

Received: 26 March 2021 / Accepted: 29 October 2021 / Published online: 8 November 2021 This is a U.S. government work and not under copyright protection in the U.S.; foreign copyright protection may apply 2021

\begin{abstract}
This paper studies the information efficiency of BRICS currency markets during the COVID-19 pandemic using daily data spanning 3rd February 2020-31st August 2021. In our preliminary analysis, which consists of tests for random walk and martingale processes, we provide evidence of time-varying weak-form market efficiency in the currency markets. In our main empirical analysis, we use wavelet coherence tools to examine the time-frequency relationship between COVID-19 death rates and BRICS currency returns, and we find higher frequency components dominate periods of panic and financial turmoil. However, subsequent to government intervention in financial markets and the more recent rollout of mass vaccination programmes, we find that higher frequency oscillations disappear, and only very low-frequency co-movements remain. Important academic, market and policy implications derived from our study are discussed.
\end{abstract}

Keywords Coronavirus - Currency returns · Efficient market hypothesis (EMH) · Adaptive market hypothesis $(\mathrm{AMH}) \cdot$ Emerging markets $\cdot$ Wavelet coherence

JEL Classification $\mathrm{C} 02 \cdot \mathrm{C} 22 \cdot \mathrm{E} 44 \cdot \mathrm{F} 31 \cdot \mathrm{G} 15$

\section{Introduction}

The advent of the COVID-19 pandemic has resurrected the debate on the validity of informational market efficiency in financial markets. Up-to-date, the research on market efficiency during the coronavirus pandemic has been dominated by enquires into equity markets (Frezza et al, 2021; Vasileiou (2021); Vasileiou et al. 2021; Okorie and Lin, 2021, Wang and Wang, 2021), cryptocurrency markets (Mnif, 2020;

Andrew Phiri

phiricandrew@gmail.com

1 Department of Economics, Faculty of Business and Economic Studies, Nelson Mandela

University, Port Elizabeth 6031, South Africa 
Naeem et al., 2021; Goodell and Goute, 2021) and more recently on currency markets (Aslam et al., 2020; Gunay, 2021; Umar and Gubareva, 2020; Xu and Lien, 2021; Yameni, 2021; Li et al., 2021; Narayan, 2020; Narayan et al., 2020; Iyke, 2020; Feng et al, 2021). Investigating market efficiency in exchange rates during the pandemic is important since currencies are the most traded asset in financial markets and are vulnerable to speculative attacks which could threaten the stability of the entire financial system. Moreover, currency markets are financial institutions which are more vulnerable to market crash since, unlike equity markets, currency exchanges do not have 'circuit breakers' mechanisms as indicators of market despair, such as those which were triggered in US stock markets and other international exchanges in mid-March 2020 (Ozkan, 2021). Examining market efficiency in currency exchanges in emerging markets during the COVID-19 pandemic is of particular interest, considering that currencies in emerging economies have been historically prone to speculative attacks and crises (Pazarbasioglu and Otker, 1997).

Our study examines informational efficiency of currency markets in BRICS economies as the most advanced emerging economies over the last few decades (Xu and Lien, 2021). We consider the BRICS countries an interesting case study since these economies mutually experienced unprecedented increases in capital outflows during the pandemic as investors shifted large amounts of capital from emerging markets to safe-haven assets (Beirne et al., 2020). This, in turn, led to significant distortions in the BRICS currency markets requiring Central Banks to make direct and indirect interventions in currency markets. Recent literature further identifies a number of COVID-related events such as the announcements of lockdowns, travel bans, government interventions (Narayan et al, 2021; Goodell, 2020), the geopolitical oil price war between Saudi Arabia and Russia (Jefferson, 2020) as well as the recent rollout of vaccines (Rouatbi et al., 2021) which have had significant impacts on global financial markets. Some other literature further finds spillover effects from the stock exchanges and oil markets into currency markets in developing countries (Narayan et al., 2020).

Our study treats the coronavirus pandemic as a natural experiment to test the informational efficiency in currency markets, that is, we question whether public information from the coronavirus health statistics can be used to predict movements in exchange rate returns and offer market participants the opportunity to beat the market through speculative behaviour. Whilst acknowledging the existence of recent literature which has examined the efficiency of international currency markets during the pandemic (Aslam et al., 2020; Umar and Gubareva, 2020; Narayan, 2020; Iyke, 2020) as well as the literature for individual BRICS countries (Gunay, 2021; Li et al., 2021) or the entire BRICS group (Xu and Lien, 2021), this current study differs from the previous literature in two ways.

Firstly, this study uses a longer time series than those used in previous studies. As far as we are concerned only the more recent studies of $\mathrm{Xu}$ and Lien (2021) and Li et al. (2021) use data which covers the 2021 period whilst the remaining studies cover periods extending to as far as November 2020. Therefore, most previous studies fail to account for recent events such as the announcement of second lockdowns in December 2020, the announcement of discovery of alpha and beta variants of the COVID virus, the US presidential elections, the capitol riots in January 2021, the 
rollout of vaccines as well as the more recent announcement of delta variant in April 2021. Furthermore, we point out that the more recent studies of $\mathrm{Xu}$ and Lien (2021) covers a period up to April 2021 and May 2021, respectively, these sample periods do not cover more recent events such as the Kabul airport bombings following the Taliban's hostile takeover of the Afghanistan government, which have had adverse effects on financial markets. This current study uses more extensive data coverage from 3rd February 2020 to 31st August 2021 for empirical purposes.

Secondly, we methodologically differ from previous studies by making use of continuous wavelet transforms to examine the lead-lag co-movement between global COVID-19 statistics and exchange rate returns in BRICS countries across time and frequency domains. The use of wavelet coherence tools allows us to examine the changing strength and duration of the co-movements between the variables in a time-varying fashion hence accommodating the adaptive market hypothesis (AMH) of Lo (2004) which advocates for financial markets evolving as a switching process between market efficiency and inefficiency. Evidence of AMH has been previously found for currency returns in developing economies (Katusiime et al., 2015), emerging economies (Al-Khazali et al., 2011) and advanced economies (Neely et al., 2007; Charles et al., 2012) albeit these studies using rolling regression windows to capture time-variation in the series. Not only do wavelets endogenously model timevariation in market efficiency, but they simultaneously allow us to examine market efficiency at different cyclical frequencies which we treat as being analogous to capturing nonlinearities and asymmetries in exchange rate returns such as those recently modelled by Yang et al. (2019) and Han et al. (2020).

Our study presents a fresh empirical perspective on market efficiency in currency markets during the COVID-19 pandemic. In our preliminary analysis, we use timedomain techniques to investigate of random walk and martingale process existing in BRICS currency series whilst in our main empirical analysis we use continuous wavelet transforms to examine semi-strong-form market efficiency in a time-frequency domain. Our findings produce evidence of changing informational market efficiency during the pandemic with currency markets being more informational efficient subsequent to government interventions in financial markets as well as the recent roll out of mass vaccination programmes. All-in-all, our study has important implications for academics, market participants and policymakers.

The rest of the study is presented as follows. The next section presents our literature review. The third section outlines our methods. The fourth section presents the data, empirical analysis and discussion of the results. The fifth section concludes the study.

\section{Literature review}

The market efficiency hypothesis (EMH), introduced by Fama (1970), states that investors cannot use previous historical information (weak-form efficiency), publicly available information (semi-strong-form efficiency) and/or privately held information (strong-form efficiency) to beat financial markets and obtain abnormal returns from investments. However, the theoretical validity of the EMH has been challenged 
on three arguments. Firstly, Grossman and Stiglitz (1980) cast doubt on the EMH due to informational asymmetries in which equilibrium in markets can only occur if there is no information existing in markets. The authors particularly argue that in the existence of information and the costs of obtaining it "... prices cannot perfectly reflect the information which is available, since if it did, then those who spend resources to get it would receive no compensation ...". Secondly, behavioural economists have emphasized on psychological and sociological elements of stock price determination and strongly believe that stock prices must be at least predictable based on past behaviour and other valuation metrics (Malkiel, 2003; Shiller; 2003, 2014). Lastly, Lo (2004) provides a 'hybrid', explanation for the violation of the EMH, by replacing the argument of rational expectations with unbounded rationality or hyperrational expectations and combines this with evolutionary aspects of economic behaviour such that survival is the core principle determining the evolution of financial markets. In this framework, profit/utility maximization and general equilibrium are part of a wider 'market ecology' and hence "...investment strategies will also wax on wane, performing well in certain environments and performing poorly in other environments ... [or] ... such [that the arbitrage opportunities in investments] may decline for a time, and then return to profitability when environment conditions become more conducive...".

From an empirical perspective, the EMH has been extensively studied for currency markets and has predominantly focussed on the weak-form EMH, that is, investigating for random walk or martingale processes within currency returns. Notably, the literature has mainly relied on six classes of econometric models for empirical purposes, namely, (i) autocorrelation tests (ii) variance ratio tests (iii) spectral shape tests (iv) runs test (v) filter and moving-average (MA) rules (vi) Markov-switching models. Extensive reviews of the literature are conveniently discussed by Cornell and Dietrich (1978) and Park and Irwin (2007) for earlier studies conducted in the 1970s and 1980s; and by Neely et al. (2009), Charles et al. (2012) and Katusiime et al. (2015) for studies conducted in the 1990s and 2000s. In summary, studies conducted in the 1960s and 1970s were concerned with examining efficiency in context of introduction of floating exchange rates as a replacement for the Bretton Woods system of fixed exchange rate, whereas studies in 1990s and 2000s focussed on the effects of the Asian Financial crisis of 1998-1999 and the global financial crisis of 2007-2009 as well as the effects of changes in exchange rate policy in response to crisis. Collectively, the findings from these previous studies do not unanimously support the EMH in currency markets and can, at best, be described as being ambiguous.

More recently, a consensus has emerged on currency markets confirming to the adaptive markets hypothesis (AMH) of Lo (2001). For instance, Al-Khazali et al. (2011) study the EMH for seven Asian currencies and the Australian dollar between 1993 and 2008 using the automatic variance ratio (AVR) tests of Choi (1999). Splitting their data into two sub-periods corresponding to the pre- and post-Asian financial crisis the authors find the currencies are more efficient in the post-crisis after the policy-regime shift to free-floating exchange rates. Charles et al. (2012) examine the time-varying return predictability of currency returns for Australia, Britain, Canada, Japan and Switzerland against the dollar between January 1974 and July 
2009 using tests for linear and non-linear dependence over fixed-length moving subsample windows. The authors find that currency returns are mostly unpredictable except during periods of coordinated Central Bank intervention and financial crisis. Katusiime et al., (2015) investigates EMH in the Ugandan currency market between January 1994 and June 2012 using a battery of parametric and non-parametric tests for random walks. The authors split the data into four sub-samples with fixed moving sample windows and find that predictable patterns in Ugandan Shillings yield less excess returns over time and once transaction costs are accounted for then trading rules are ineffective. Yang et al. (2019) investigate the EMH for the Swiss/Euro exchange rate using the detrending moving average (DMA) and the detrended fractal analysis (DFA) between January 2001 and August 2017. The authors split their data into five sub-samples corresponding to different monetary regimes for the Swiss National Bank (SNB) and confirm market efficiency for every regime except for times when the SNB intervened in currency markets and during financial and debt crises of late 2009/2010. Han et al. (2020) use a multifractal DFA (i.e. MF-DFA) analysis to study the multifractal properties of returns on Euro, Britain, Canada and Japan against the dollar across three sub-sample dictated by 2008 financial crisis and the 2014 end of quantitative easing. The authors find that the GFC and the monetary policy adjustments have greater effect on multifractal properties and inefficiency of the currency markets.

As previously mentioned in the paper's introduction, there have been a handful of more recent studies which have examined different forms of market efficiency in currency exchanges during the COVID-19 pandemic. Iyke (2020) examined the 'disease outbreak channel' of exchange rate predictability for 17 bilateral exchange rates inclusive BRICS currency exchanges. Using a GARCH model, the author finds evidence against the semi-weak form of EMH as the author finds that information from COVID-19 statistics has better one-day predictability for exchange rate returns and better five-day prediction power for volatility.

Narayan (2020) uses an endogenous structural break unit root tests on the USDJPY exchange rate and finds that COVID-19 has changed the resistance of the Yen to shocks and the currency has become inefficient during the pandemic. Aslam et al. (2020) investigated market efficiency in 6 industrialized currency markets (AUD, CAD, CHF, EUR, GBP and JPY) for periods before and during the pandemic using the multifractal detrended analysis (MFDA) and find varying degrees of efficiency between the periods. Umar and Gubareva (2020) investigate the interdependence between the COVID-19 panic index and EUR, GBP and RMB currencies using wavelet coherence analysis and find strong negative coherence between the panic index and exchange rates.

Feng et al. (2021) examine the impact of COVID-19 and government interventions on the volatility of the EUR, RMB, GBR and JPN currencies using generalized methods of moments (GMM) and find that whilst an increase in COVID-19 cases is associated with an increase in currency volatility and government interventions have helped reduce exchange rate volatility. Gunay et al. (2021) uses standalone risk analysis and dynamic volatility spillover analysis to compare the shockwave effect between COVID-19 and the global financial crisis (GFC) for the USD against six currencies EUR, GBP, JPY, CNY, BRL and TRY. The standalone analysis shows 
that the turmoil from the COVID-19 shocks was not as severe as the GFC and yet the shockwave from volatility spillover analysis is found to be significantly stronger in the COVID-19 compared to the GFC. Li et al. (2021) use an autoregressive distributive lag (ARDL) model to examine the impact of COVID-19 health statistics between the CNY-USD exchanges and find a negative relationship between the currencies and COVID cases and deaths. Xu and Lien (2021) use GARCH and Copula-based generalized autoregressive score (GAS) approach to measure currency interdependencies in BRICS currency markets during the pandemic. The authors use a dummy variable approach to split their data into four sub-samples corresponding to incubation (27th December 2019-19th January 2020), fever (20th January 2020-17th March 2020), moderation (18th March 2020-28th April 2020) and normalization (29th April 2020-26th April 2021). The findings indicate a negative effect of COVID-19 on the dependency of CNY and the other BRICS countries.

Our study builds on the literature and investigates market efficiency in BRICS markets using more recent time series and more sophisticated methodology. This is important since previous literature focuses on strict use of time-domain econometric techniques which do not consider possible frequency varying relationships which are important for understanding changes in market efficiency. By making use of continuous wavelet transforms, we are able to capture both time-varying and frequency varying co-movements between COVID-19 death rates and currency returns in BRICS markets. Computational details of this methodology are provided in the next section.

\section{Methods}

Wavelets were initially introduced by mathematicians but quickly became popularized in other fields of science such as geophysics, neurosurgery, meteorology, engineering and statistics ((Torrence and Compo, 1998) and only more recently has the methodology gained traction amongst financial economists who primarily use these techniques to extract the signal features of financial time series data across a time-frequency plane (Aguiar-Conraria and Soares, 2010, 2014). Wavelets are small waves that grow and decay in a limited time period and are made up of two distinct parameters: time $(\tau)$ and scale (s). Wavelet analysis is based on the convolution of the time series with a set of 'daughter' wavelets and is used to decompose a signal or time series across a time-frequency plane. These transforms can either be discrete (returns data vector of the same length as the input signal) or continuous (returns an output vector which is one dimension higher than the input). In our study, we use continuous wavelet transform (CWT) for a wavelet $\psi$ which can be defined as follows:

$$
W_{x}(s,)=\int_{-\infty}^{\infty} x(t) \frac{1}{\sqrt{s}} *\left(\frac{t-}{s}\right) d t
$$


where * denotes a complex conjugation, $\tau$ is the translation parameter and $s$ is the scaling parameter controlling the length of the wavelet. To explore the instantaneous phase information in the time-scale plane, we make use of the Morlet wavelet as the analytical complex 'mother' wavelet which is defined as:

$$
(t)=-\frac{1}{4} \exp \left(i_{0} t\right) \exp \left(-\frac{1}{2} t^{2}\right)
$$

To ensure that the parameterization of the Morlet wavelet depicts an inverse relation between wavelet scales and the frequencies, $\mathrm{f} \approx s^{-1}$, the Morlet is set at $2 \pi$ in order for the wavelet scale, $s$, to be almost equal to the Fourier period (Aguiar-Conraria and Soares, 2010, 2014). The wavelet power spectrum (WPS) for a discrete time series, $x_{n}$, measures the variance of a time series across a two-dimension plane i.e. time and scale, and is computed as:

$$
W_{m}^{s}(s)=\frac{t}{\sqrt{s}} \sum_{n=0}^{N-1} x_{n} *\left((n-m) \frac{t}{s} n=0, \ldots, N-1, m=0, \ldots, N-1\right.
$$

where $\delta \mathrm{t}$ is a uniformed time step. By defining the WPS of $\mathrm{x}(\mathrm{t})$ and $\mathrm{y}(\mathrm{t})$ as $\mathrm{W}_{\mathrm{xx}}=\left|\mathrm{W}_{\mathrm{x}}\right|^{2}$ and $\mathrm{W}_{\mathrm{yy}}=\left|\mathrm{W}_{\mathrm{y}}\right|^{2}$, respectively, the cross-wavelet power spectrum (CWPS), which is analogous to the covariance between $x(t)$ and $y(t)$ in time-frequency domain, is computed as:

$$
(W P S)_{x y}=W_{x y}=\left|W_{x y}\right|
$$

Then the wavelet coherence, which is analogous to the correlation between $\mathrm{x}(\mathrm{t})$ and $y(t)$ across time and frequency, is computed as the ratio of the cross spectrum to the product of the spectrums of the individual series i.e.

$$
R_{n}(s)=\frac{S\left(W_{x y}\right)}{\left[\left(S W_{x}^{2}\right)\left(S W_{y}^{2}\right)\right]^{\frac{1}{2}}}
$$

where $\mathrm{S}$ is a smoothing operator in both time and scale. To distinguish between negative and positive correlation between a pair of time series as well as identifying lead-lag causal relationships between the variables, we make use of phase-difference dynamics we are defined as:

$\left.x, y=\tan ^{-1}\left(\frac{\left\{W_{x}\right\}}{\left\{W_{x}\right\}}\right)\right)$.(6).where $\phi_{\mathrm{x}, \mathrm{y}}$ is parametrized in radians, bound between $\pi$ and - $\pi$. If $\phi_{x, y} \in\left(0, \frac{\pi}{2}\right)$ and $\phi_{x, y} \in\left(0,-\frac{\pi}{2}\right)$, then the series is said to be in-phase (positive correlation) with $\mathrm{y}$ leading $\mathrm{x}$ in the former and $\mathrm{x}$ leading $\mathrm{y}$ in the latter. Conversely, If $\phi_{\mathrm{x}, \mathrm{y}} \in\left(\frac{\pi}{2}, \pi\right)$ and $\phi_{\mathrm{x}, \mathrm{y}} \in\left(-\frac{\pi}{2},-\pi\right)$, then the series are said to be in an anti-phase (negative correlation) with $\mathrm{x}$ leading $\mathrm{y}$ in the former and $\mathrm{y}$ leading $\mathrm{x}$ in the latter. A phase-difference of zero implies co-movement between the pair of series at the specified frequency. 


\section{Data and preliminary analysis}

\subsection{Data description}

Our study uses daily data of global COVID-19 death rates, from the Worldometer database, and exchange rates of BRICS currencies in US dollars, sourced from the Bank of England (BoE) databases, covering the period of 3rd February 2020 to 31st August 2021. The COVID-death rates are computed as the fraction of global deaths in total cases and are, in effect, the reciprocal of the global COVID-19 recovery rates, whereas we compute the returns on the exchange rates as $\log \left(E R_{t} /\right.$ $\left.E R_{t-1}\right) \times 100 \%$. Table 1 reports the descriptive statistics of the time series variables whilst Fig. 1 presents the corresponding time series plots of the variables.

\subsection{Preliminary analysis}

This section presents preliminary empirical analysis examining the weak-form efficiency for currency returns for each of the BRICS countries using three classes of testing procedures prescribed by Aumeboonsuke and Dryver (2014) for detecting random walk and martingale processes existing in financial series i.e. autocorrelation tests, variance ratio tests and runs test. In addition, we follow the approaches of AlKhazali et al. (2011), Charles et al. (2012) and Katusiime et al., (2015) by applying fixed rolling windows regressions, and, in our case, we draw from recent 'COVIDrelated' literature to determine the 'break dates' used to create the different window periods. Firstly, we draw from the study of Xu and Lien (2021) who identified five sub-periods of interest during the pandemic, namely, incubation (27th December 2019-19th January 2020), fever (20th January 2020 -17th March 2020), moderation (18th March 2020-28th April 2020) and normalization (29th April 2020-26th April 2021). Secondly, we draw from the study of Rouatbi et al (2021) who identify a more recent 'immunization period', starting on the 1st January 2021, and find that the increasing number of vaccinated people during this period has contributed towards recent financial market stability. Collectively, our study makes use of rolling window periods corresponding to (i) fever period (3rd February 2020-17th March

Table 1 Summary statistics of time series

\begin{tabular}{lllllll}
\hline & COVID-19 & $\begin{array}{l}\text { Brazil } \\
\text { BRL/USD }\end{array}$ & $\begin{array}{l}\text { Russia } \\
\text { RUB/USD }\end{array}$ & $\begin{array}{l}\text { India } \\
\text { INR/USD }\end{array}$ & $\begin{array}{l}\text { China } \\
\text { CNY/USD }\end{array}$ & $\begin{array}{l}\text { South Africa } \\
\text { ZAR/USD }\end{array}$ \\
\hline Mean & 6.1598 & -0.0147 & -0.0107 & -0.0017 & 0.0063 & 0.0021 \\
Std. dev & 5.9433 & 0.4519 & 0.3731 & 0.1307 & 0.0919 & 0.3632 \\
Min & 2.2700 & -1.9535 & -3.7305 & -0.7175 & -0.4266 & -1.6804 \\
Max & 39.8500 & 1.6182 & 1.3521 & 0.8442 & 0.6204 & 1.0666 \\
JB $(p$-value $)$ & 0.0000 & 0.0000 & 0.0000 & 0.0000 & 0.0000 & 0.0000 \\
Obs & 577 & 577 & 577 & 577 & 577 & 577 \\
\hline
\end{tabular}

$* * *, * *, *$ denote the $1 \%, 5 \%$ and $10 \%$ significance levels, respectively. Lag lengths of unit root tests reported in (). $\mathrm{P}$-values report for runs test and variance ration (VR) test 

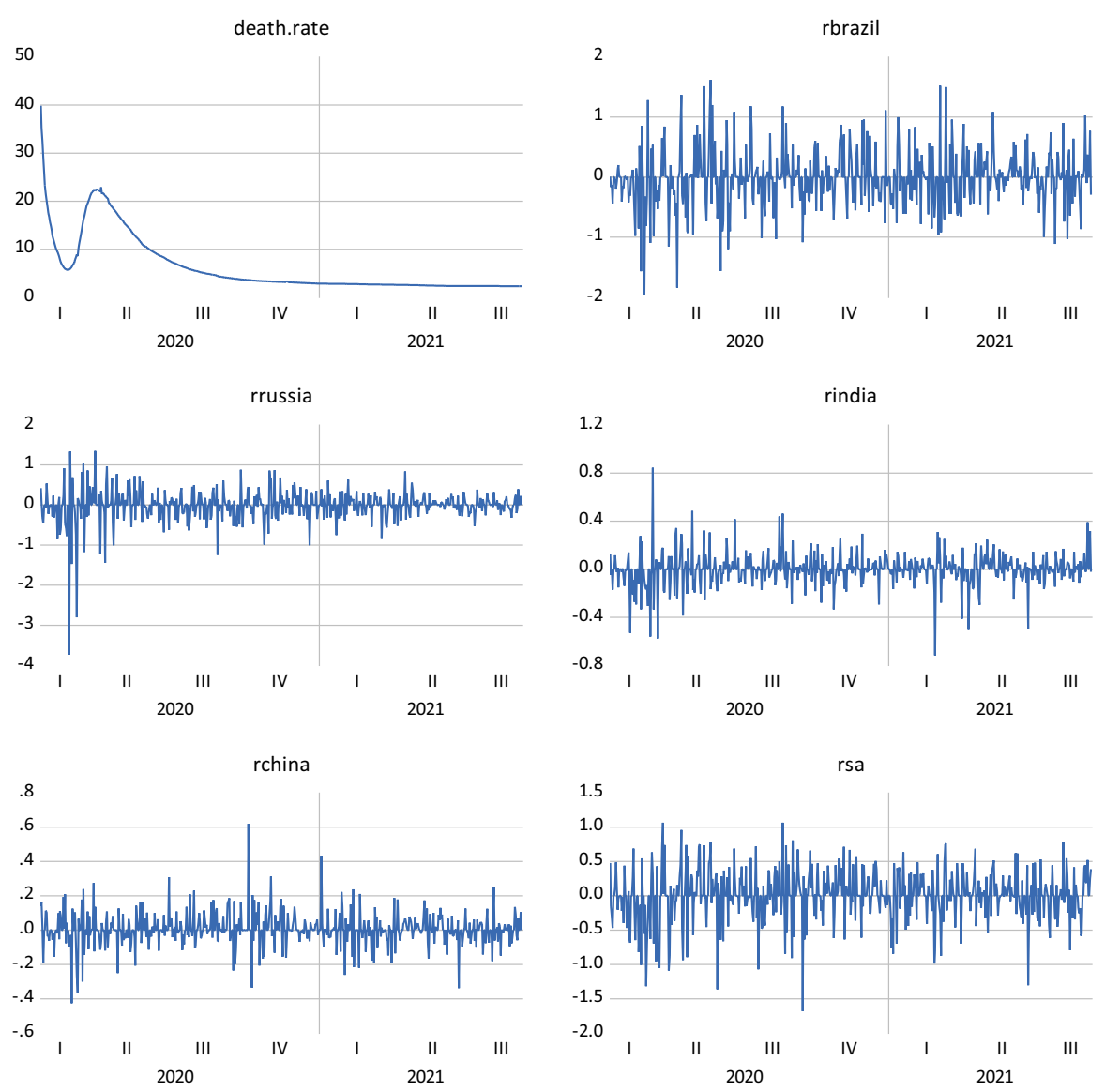

Fig. 1 Time series plots

2020) (ii) moderation period (18th March 2020-29th April 2020) (iii) normalization period (29th April 2020-26th April 2021) (iv) immunization period (1st January 2021-30th August 2021).

Firstly, we compute the Ljung-Box (LB) Q-statistic for the currency return series which tests the null hypothesis of serial correlation against the alternative of random walk behaviour at different lag lengths (k). The $p$-values associated with the Q-statistic performed at lags 2, 4, 6, 8, 6 and 32 are reported in Table 2, and as can be observed, there are discrepancies in the findings over the different time samples. For the full sample 3rd February 2020-31st August 2021, we find evidence of autocorrelation for Russian, China and South Africa and no evidence is found for the Brazilian and Indian currency returns. However, we find no evidence of autocorrelation in all currency returns for the 'fever period' of 3rd February 2020-17th March 2020 as well as for the 'immunization period' of 1st January 2021-31st August 2021. For the remaining sub-samples, we find evidence of autocorrelation in Chinese 
Table 2 Autocorrelation tests

\begin{tabular}{|c|c|c|c|c|c|c|}
\hline Period & $\mathrm{K}$ & Brazil & Russia & India & China & South Africa \\
\hline \multirow[t]{5}{*}{ 3rd February 2020-31st August 2021} & 2 & 0.463 & 0.101 & 0.588 & $0.024 * *$ & $0.022 * *$ \\
\hline & 4 & 0.683 & $0.058^{*}$ & 0.542 & $0.051^{*}$ & $0.072 *$ \\
\hline & 8 & 0.377 & $0.001 * * *$ & 0.170 & 0.166 & $0.061 *$ \\
\hline & 16 & 0.780 & $0.001 * * *$ & 0.313 & 0.525 & $0.065^{*}$ \\
\hline & 32 & 0.577 & $0.001 * * *$ & 0.491 & 0.463 & 0.182 \\
\hline \multirow[t]{5}{*}{ 3rd February 2020-17th March 2020} & 2 & 0.628 & 0.379 & 0.546 & 0.935 & 0.938 \\
\hline & 4 & 0.390 & 0.231 & 0.839 & 0.963 & 0.893 \\
\hline & 8 & 0.305 & 0.618 & 0.990 & 0.562 & 0.848 \\
\hline & 16 & 0.726 & 0.609 & 0.819 & 0.526 & 0.668 \\
\hline & 32 & 0.980 & 0.988 & 0.997 & 0.758 & 0.657 \\
\hline \multirow[t]{5}{*}{ 18th March 2020-28th April 2020} & 2 & 0.415 & 0.289 & 0.438 & $0.003 * * *$ & 0.112 \\
\hline & 4 & 0.691 & 0.557 & 0.499 & $0.017 * *$ & 0.311 \\
\hline & 8 & 0.344 & 0.405 & 0.433 & 0.120 & $0.005 * * *$ \\
\hline & 16 & 0.562 & 0.317 & 0.567 & 0.417 & $0.028 * *$ \\
\hline & 32 & 0.657 & 0.618 & 0.803 & 0.725 & 0.232 \\
\hline \multirow[t]{5}{*}{ 29th April 2020-31st December 2020} & 2 & 0.301 & 0.999 & $0.097 *$ & 0.347 & $0.039 *$ \\
\hline & 4 & 0.399 & 0.979 & 0.240 & 0.310 & $0.095 *$ \\
\hline & 8 & 0.516 & 0.689 & 0.341 & 0.237 & 0.285 \\
\hline & 16 & 0.906 & 0.372 & 0.231 & 0.568 & 0.173 \\
\hline & 32 & 0.729 & 0.202 & 0.480 & 0.651 & 0.282 \\
\hline \multirow[t]{5}{*}{ 1st January 2021-30th August 2021} & 2 & 0.824 & 0.873 & 0.434 & 0.116 & 0.252 \\
\hline & 4 & 0.948 & 0.777 & 0.317 & 0.305 & 0.247 \\
\hline & 8 & 0.783 & 0.918 & 0.176 & 0.194 & 0.537 \\
\hline & 16 & 0.753 & 0.937 & 0.577 & 0.352 & 0.799 \\
\hline & 32 & 0.708 & 0.791 & 0.426 & $0.087^{*}$ & 0.932 \\
\hline
\end{tabular}

$* * *, * *, *$ denote the $1 \%, 5 \%$ and $10 \%$ significance levels, respectively

and South African currency returns during the 'moderation period' of 18th March 2020-28th April 2020, and in Indian and South African currency returns during the 'normalization period' of 29th April 2020-30th December 2020. Note that solely for Brazilian and Russian currency returns do we not find evidence of autocorrelation in the returns series across all sub-samples, supporting the weak-form EMH, whilst for the remaining currencies (India, China and South Africa) there is evidence of timevarying efficiency, which conforms to the $\mathrm{AMH}$.

Secondly, we apply the wild bootstrap technique of Kim (2006) to the variance ratio tests of Lo and MacKinlay (1988) to examine if martingale process exists in the currency returns data. We compute the individual statistics at lag lengths of 1,2 , 4, 816 and 32 for the different sub-samples and report our findings in Table 3. Note that the reported statistics for each of the currency returns reject the null hypothesis in favour of market inefficiency at all lags during the normalization (29th (April 2020-26th April 2021) and immunization (1st January 2021-30th August 2021) 
Table 3 Variance ratio tests

\begin{tabular}{|c|c|c|c|c|c|c|}
\hline Period & $\mathrm{K}$ & Brazil & Russia & India & China & South Africa \\
\hline \multirow[t]{5}{*}{ 3rd February 2020-31st August 2021} & 2 & $0.000 * * *$ & $0.000 * * *$ & $0.000 * * *$ & $0.000 * * *$ & $0.000 * * *$ \\
\hline & 4 & $0.000 * * *$ & $0.000 * * *$ & $0.000 * * *$ & $0.000 * * *$ & $0.000 * * *$ \\
\hline & 8 & $0.000 * * *$ & $0.003 * * *$ & $0.000 * * *$ & $0.000 * * *$ & $0.000^{* * *}$ \\
\hline & 16 & $0.001 * * *$ & $0.028 * *$ & $0.001 * * *$ & $0.000 * * *$ & $0.001 * * *$ \\
\hline & 32 & $0.008 * * *$ & $0.069^{*}$ & $0.020 * *$ & $0.013 * *$ & $0.008 * * *$ \\
\hline \multirow[t]{5}{*}{ 3rd February 2020-17th March 2020} & 2 & $0.045^{*}$ & 0.246 & $0.039 *$ & $0.030 *$ & $0.035^{*}$ \\
\hline & 4 & $0.058 *$ & 0.273 & 0.119 & $0.088 *$ & $0.043 *$ \\
\hline & 8 & 0.204 & 0.266 & 0.138 & $0.097 *$ & $0.073^{*}$ \\
\hline & 16 & 0.322 & 0.217 & 0.143 & 0.163 & 0.182 \\
\hline & 32 & 0.463 & 0.422 & 0.278 & 0.489 & 0.634 \\
\hline \multirow[t]{5}{*}{ 18th March 2020-28th April 2020} & 2 & $0.016 * *$ & $0.008 * * *$ & $0.045^{*}$ & $0.011 * *$ & $0.041 *$ \\
\hline & 4 & $0.086^{*}$ & $0.046^{*}$ & $0.040^{*}$ & $0.068 *$ & $0.080 *$ \\
\hline & 8 & 0.100 & 0.131 & $0.092 *$ & 0.102 & 0.202 \\
\hline & 16 & 0.183 & 0.225 & 0.111 & 0.152 & 0.258 \\
\hline & 32 & 0.754 & 0.936 & 0.344 & 0.387 & 0.897 \\
\hline \multirow[t]{5}{*}{ 29th April 2020-31st December 2020} & 2 & $0.000 * * *$ & $0.000 * * *$ & $0.000 * * *$ & $0.000 * * *$ & $0.000 * * *$ \\
\hline & 4 & $0.000 * * *$ & $0.000 * * *$ & $0.000 * * *$ & $0.000 * * *$ & $0.000 * * *$ \\
\hline & 8 & $0.000 * * *$ & $0.000 * * *$ & $0.000^{* * * *}$ & $0.002 * * *$ & $0.001 * * *$ \\
\hline & 16 & $0.007 * * *$ & $0.006 * * *$ & $0.005 * * *$ & $0.022^{* *}$ & $0.012 * *$ \\
\hline & 32 & $0.029 *$ & $0.031 *$ & $0.024 *$ & $0.048^{*}$ & $0.032 *$ \\
\hline \multirow[t]{5}{*}{ 1st January 2021-30th August 2021} & 2 & $0.000^{* * *}$ & $0.000 * * *$ & $0.000 * * *$ & $0.000 * * *$ & $0.000 * * *$ \\
\hline & 4 & $0.000 * * *$ & $0.000 * * *$ & $0.000 * * *$ & $0.000 * * *$ & $0.000 * * *$ \\
\hline & 8 & $0.001 * * *$ & $0.001 * * *$ & $0.001 * * *$ & $0.000 * * *$ & $0.000 * * *$ \\
\hline & 16 & $0.012 * *$ & $0.017 * *$ & $0.007 * * *$ & $0.011 * *$ & $0.008 * * *$ \\
\hline & 32 & $0.035^{*}$ & $0.044^{*}$ & $0.025^{* *}$ & $0.036^{*}$ & $0.026 * *$ \\
\hline
\end{tabular}

$* * *, * *, *$ denote the $1 \%, 5 \%$ and $10 \%$ significance levels, respectively

periods. Note that during the fever (3rd February 2020-17th March 2020) and moderation (18th March 2020-29th April 2020) periods, there is evidence of a martingale process in all currency returns at shorter lag lengths of 2 and 8 days with the exception of the Russian currency returns which rejects the martingale hypothesis at all lag lengths during the fever period. We treat this evidence as support in favour of the AMH particularly at higher lag lengths in which observe time-varying dynamics.

Lastly, we compute the Z-statistic derived from run's test which tests the null hypothesis that there is no difference between the actual and expected number of runs and report the findings in Table 4. We find evidence of predictability in returns for Brazilian, Chinese and South African currency returns for the full sample period; the Chinese currency returns during the fever period (3rd February 2020-17th March 2020); the Brazilian currency returns during the moderation period (18th March 2020-29th April 2020); the Brazilian and Chinese currency returns during the normalization period (29th April 2020-31st December 2020); whilst we fail to 
Table 4 Run's test

\begin{tabular}{llllll}
\hline Period & Brazil & Russia & India & China & South Africa \\
\hline 3rd February 2020-31st August 2021 & $\begin{array}{l}244.000 \\
(0.081)^{*}\end{array}$ & $\begin{array}{l}0.000 \\
(1.000)\end{array}$ & $\begin{array}{l}246.000 \\
(0.194)\end{array}$ & $\begin{array}{l}232.000 \\
(0.014)^{* *}\end{array}$ & $\begin{array}{l}239.000 \\
(0.011)^{* *}\end{array}$ \\
3rd February 2020-17th March 2020 & $\begin{array}{l}16.000 \\
(0.222)\end{array}$ & $\begin{array}{l}0.000 \\
(1.000)\end{array}$ & $\begin{array}{l}20.000 \\
(0.793)\end{array}$ & $\begin{array}{l}16.000 \\
(0.059)^{*}\end{array}$ & $\begin{array}{l}20.000 \\
(0.420)\end{array}$ \\
18th March 2020-28th April 2020 & 14.000 & 0.000 & 16.000 & 22.000 & 16.000 \\
& $(0.015)^{* *}$ & $(1.000)$ & $(0.171)$ & $(0.455)$ & $(0.249)$ \\
29th April2020-31st December 2020 & 89.000 & 0.000 & 114.000 & 98.000 & 109.000 \\
& $(0.009)^{* * *}$ & $(1.000)$ & $(0.297)$ & $(0.071)^{*}$ & $(0.279)$ \\
1st January 2021-30th August 2021 & 100.000 & 0.000 & 102.000 & 106.000 & 105.000 \\
& $(0.204)$ & $(1.000)$ & $(0.165)$ & $(0.505)$ & $(0.265)$ \\
\hline
\end{tabular}

$* * *, * *, *$ denote the $1 \%, 5 \%$ and $10 \%$ significance levels, respectively. $P$-values report in ()

find evidence of predictability in any of the currency returns during the immunization period (1st January 2020-30th August 2021). Note that for Russian and Indian, the null hypothesis of currency returns predictability is rejected at all sampled periods hence our results advocate for weak-form efficiency in Russian and Indian currency returns whilst advocating for the $\mathrm{AMH}$ in the remaining currency markets.

Overall, the preliminary analysis presents conflicting results. On one hand, the autocovariance test indicates that the currency markets have been generally weakform market efficient during the different sub-periods of the pandemic. On the other hand, the variance ratio tests show that currency markets were most efficient during the fever and moderation periods, whilst being inefficient during the normalization and immunization periods. Moreover, run's test further highlights that market efficiency has varied between countries across the fever, moderation and normalization periods but are mutually market efficient during the immunization period. Collectively, we treat our results as providing support in favour of the AMH in the weaksense form. In the next section, we use wavelet coherence images to examine the lead-lag co-movement between public information on COVID-19 death rates and currency returns and consequentially test for semi-form efficiency across a time-frequency domain.

\subsection{Wavelet coherence analysis}

Figures 2, 3, 4, 5, 6 plot the wavelet coherence between COVID-19 death rates and currency rates in the individual BRICS countries. In each of the diagrams, the interpretation of the wavelet coherence is 3-dimensional. Firstly, the time dimension is measured along the x-axis. Secondly, the frequency dimension is measured along the $y$-axis which the frequency units are converted into time units ranging from 1-day (highest frequency) to 256-days (lowest frequency). Thirdly, the strength of coherence between the pair of series is measured by the colour dimension with blue contours indicating weak correlation, green/yellow contours indicating moderate correlation and red contours representing strong correlation. Moreover, in interpreting the phase-difference dynamics which are captured with the 'arrow' orientation 

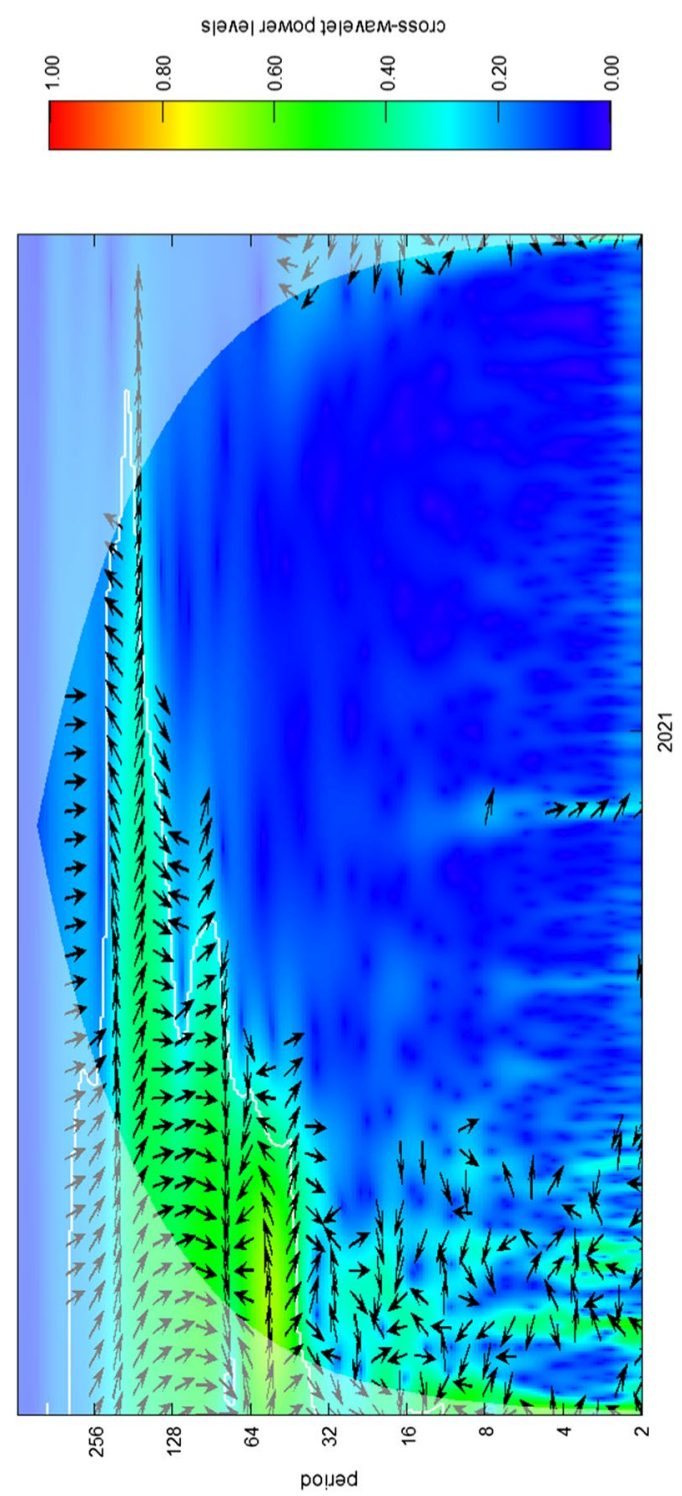

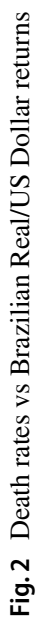




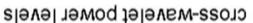
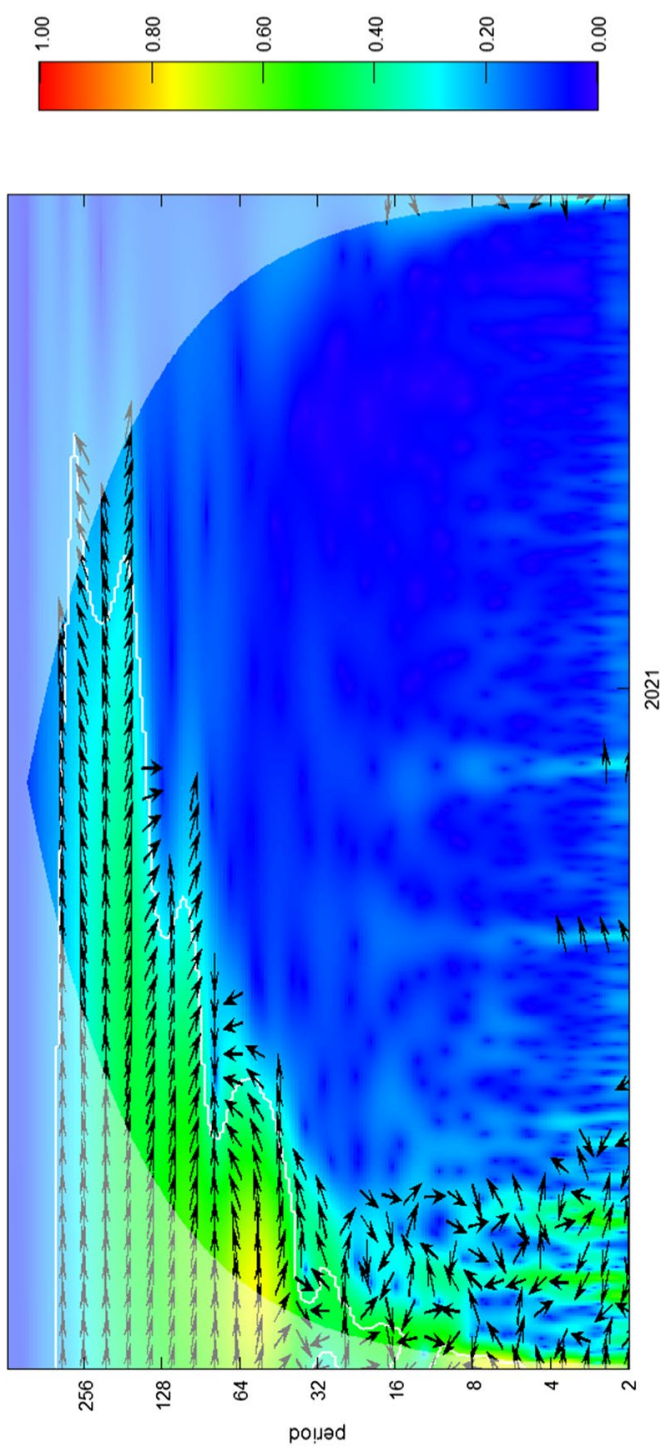

จั่

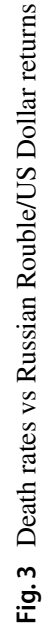



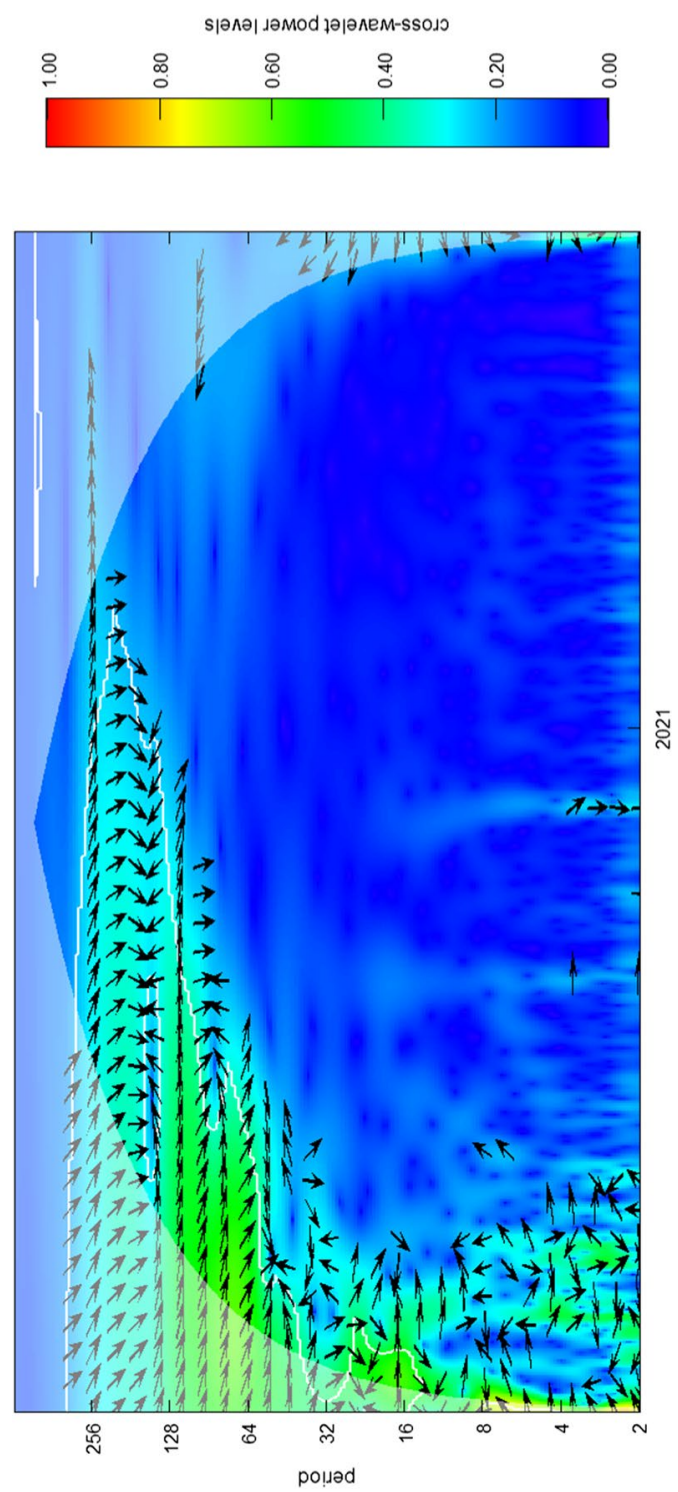

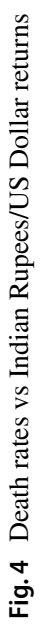



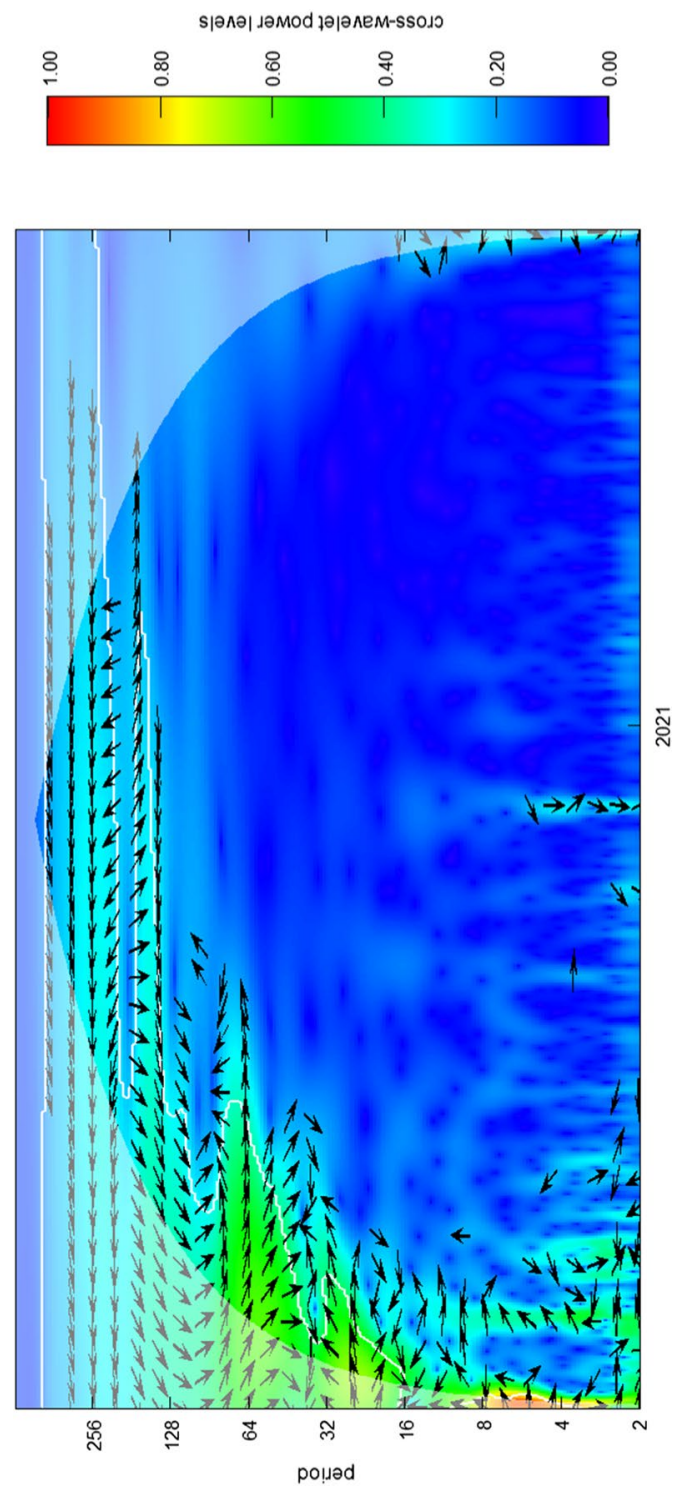

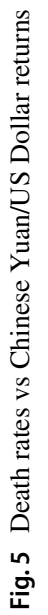



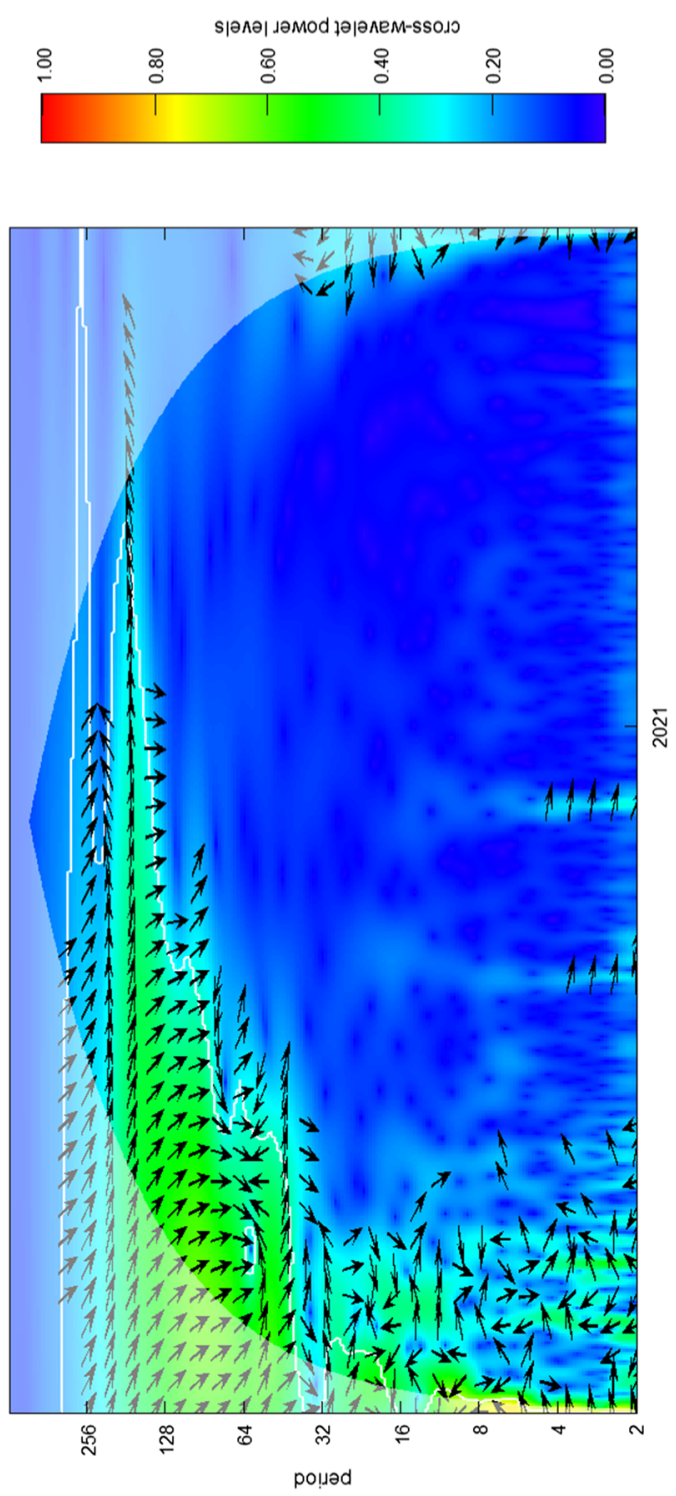

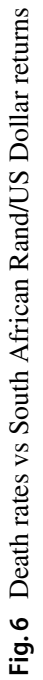


within each of the figures. The $\rightarrow(\leftarrow)$ pointed arrow denotes phase-in (phase-out) which can be interpreted as positive (negative) correlations between the series. The arrows pointing to the $\nearrow$ or $\uparrow(\swarrow)$ indicate that the coronavirus positively (negatively) leads the currency returns and all arrows facing $\searrow$ or $\downarrow(\nwarrow)$ implies that currency returns negatively (positively) leads market returns. The faint white lines surrounding the 'arrows' indicate the 5\% significance level whereas curved 'inverted U-shaped' line represents the cone of influence.

From the onset, it is interesting to note that the dynamic co-movement between COVID-19 death rates and currencies returns are similar across the BRICS economies and the observed similarities in the wavelet coherence plots can be summarized in two points. Firstly, from a time perspective, we note there exists significant co-movements between the series across the entire time domain and this finding is contrary to the semi-strong form of the efficient market hypothesis. Secondly, from a frequency perspective, we find that a higher range of significant frequency oscillations of between 8 and 256 days exist during the earlier days of the pandemic relating to the fever period. However, following the various government interventions between March and April 2020 (moderation period), we begin to see that higher frequency components of between '2-32 days' sharply lose significance to lower frequency components of '32-256 days'. Furthermore, we observe two sharp changes in frequency oscillations during the 'normalization period' (i) around August 2020 when frequency components of '32-64 days' lose their significance, and (ii) around November 2020, when oscillations of'64-128 days' lose their significance, and by the 'immunization period' starting January 2021, only low-frequency components of '128-256 days' remain significant.

In turning to the phase-difference dynamics within the wavelet coherence plots, we note that whilst a majority of the arrow orientation points to in-phase (positive) synchronizations between the COVID-19 death rates and currencies in the BRICS economies, there are two instances where anti-phase (negative) synchronizations are observed. Firstly, for the Brazilian returns, we observe anti-phase dynamics at frequency components of 64 days between March and August (fever and moderation periods). Secondly, for Chinese currency returns anti-phase behaviour is observed at much lower frequency oscillations of between 128 and 256 days. Altogether, the phase dynamics indicate a positive effect of the COVID-19 death rate on BRICS currency returns throughout the entire pandemic with the exception of Brazilian and Chinese currencies at certain frequencies.

\subsection{Sensitivity analysis}

In this section of the paper, we present a sensitivity analysis in which we use COVID-19 recovery rate, that is the total percentage number of recoveries as a fraction of cases, as a COVID health measure, and examine its time-frequency relationship with the BRICS currency returns. Based on the wavelet coherence plots between the series presented in Figs. 7, 8, 9, 10, 11, we observe similar time-frequency dynamics as those from the COVID-19 death statistics. Firstly, we observe significant co-movements between the variables across the entire time window. 

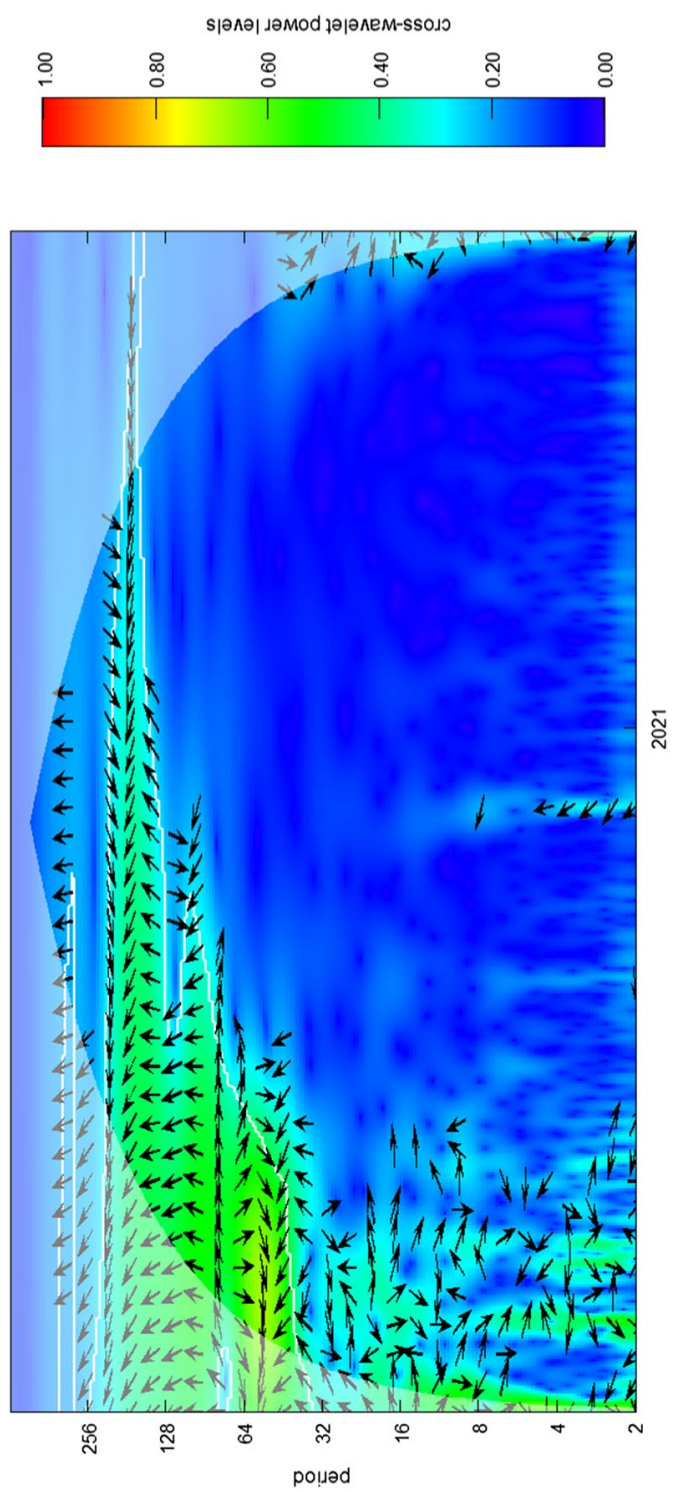

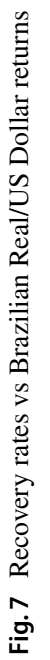



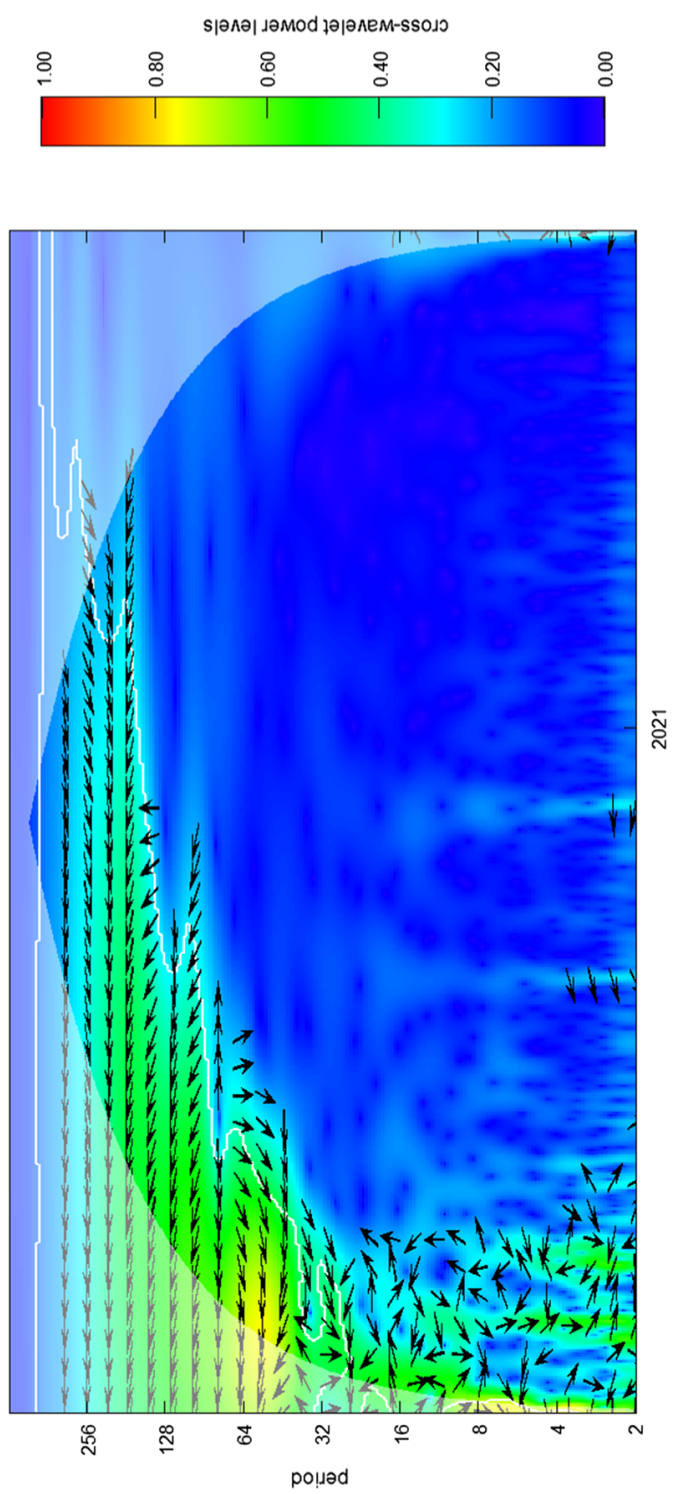

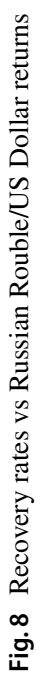


cross-wavelet power levels
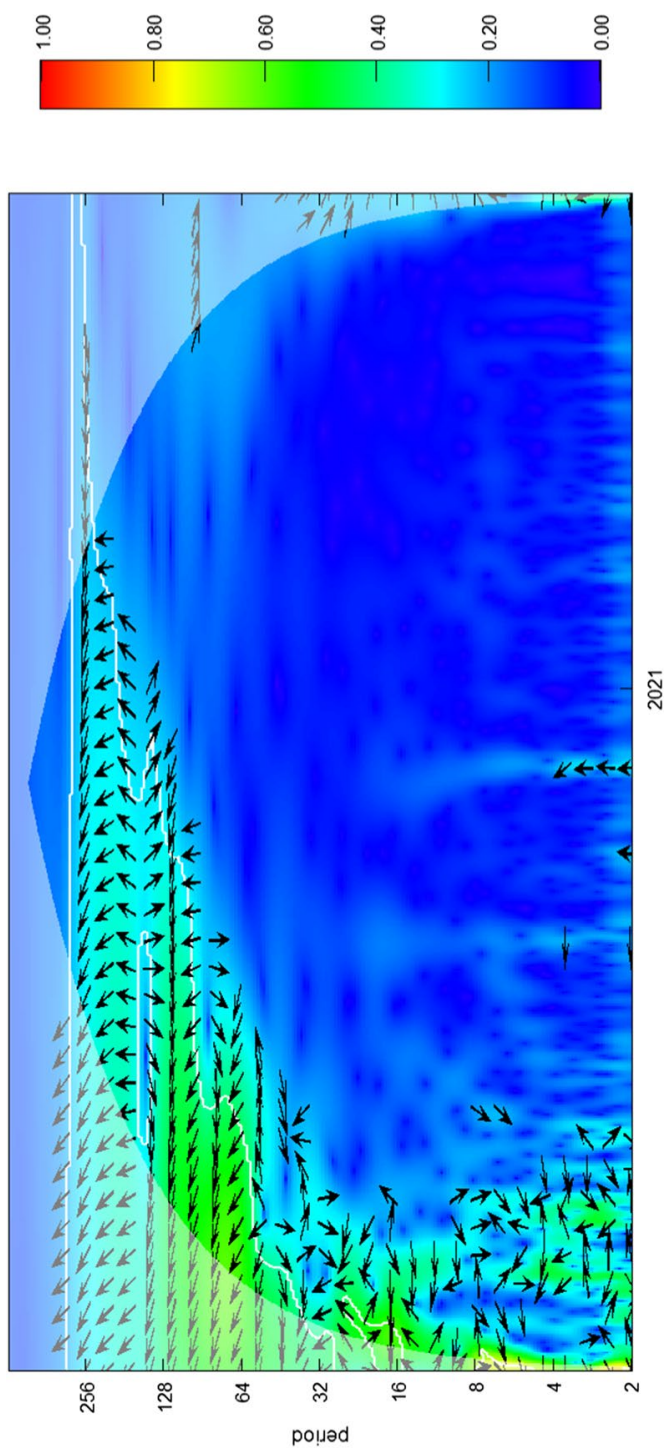

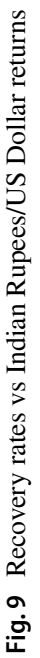




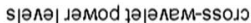
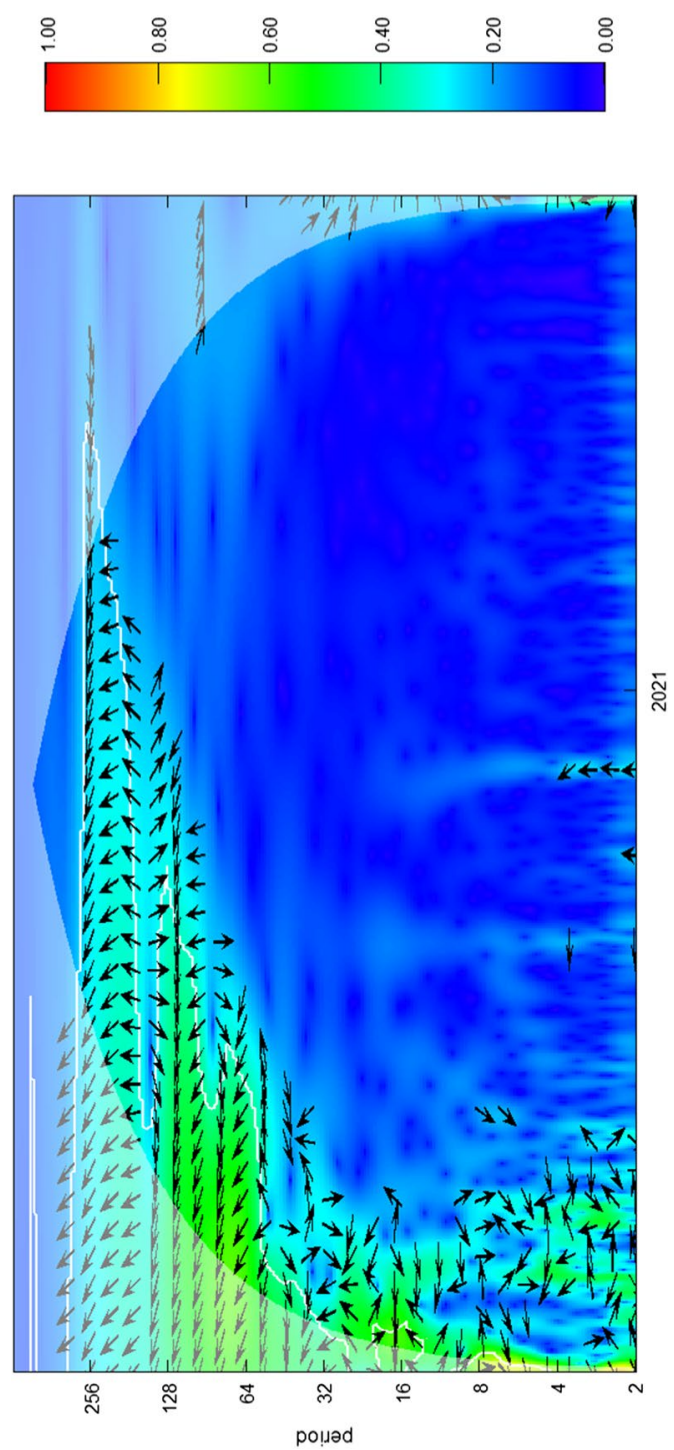

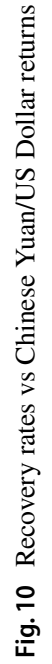


s|әмә| дәмоd дә|әмеM-ssoגว
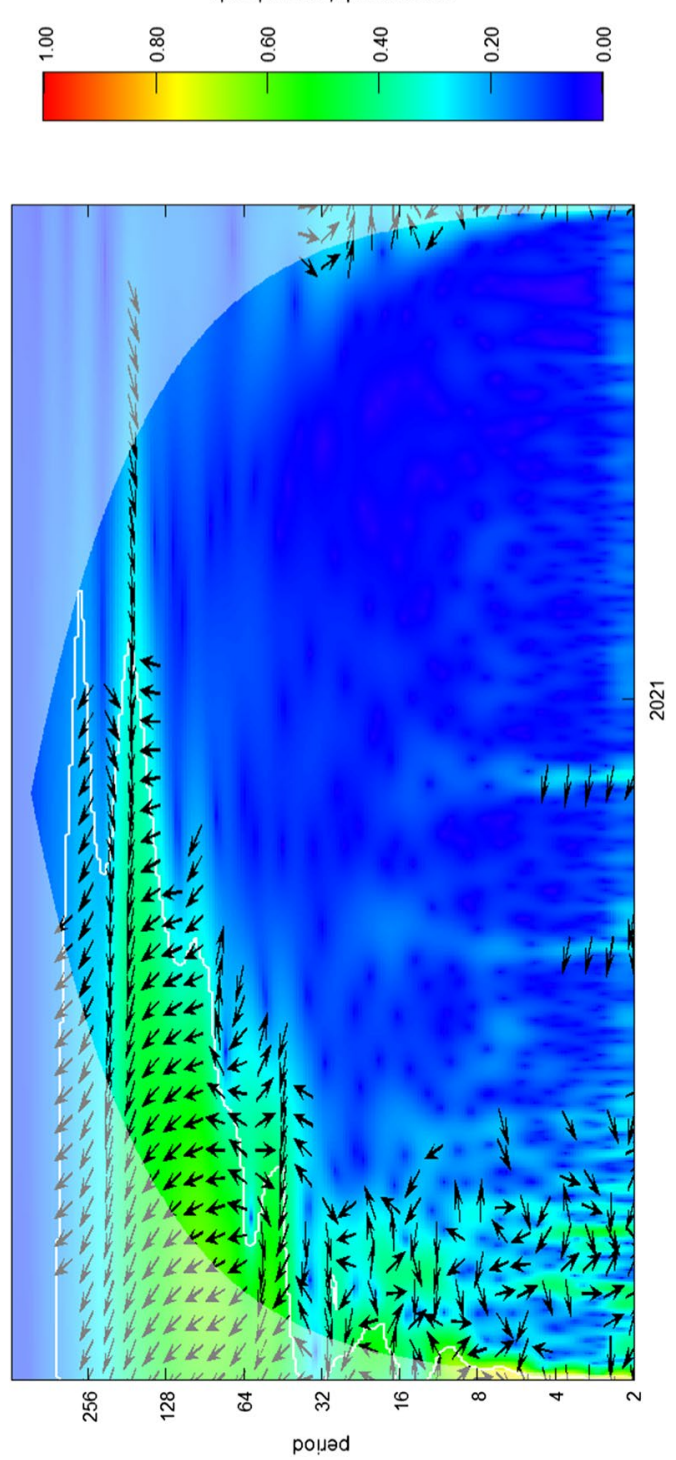

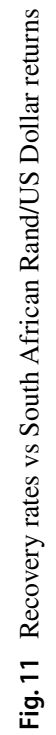


Secondly, we that the higher frequency oscillations progressively lose significance to lower frequency components and during the immunization period only frequency oscillations of between 128 and 256 days exist. Thirdly, we find the reverse phase dynamics from that were previously obtained from the COVID-19 death rate statistics. We find that whilst most periods are dominated by anti-phase (negative) oscillations throughout the wavelet plots there are exceptions for Brazilian and Chinese currency markets which display in-phase dynamics at 64-day oscillations and 128-256 day oscillations, respectively. All-in-all, the described phase dynamics are opposite to those found for the COVID-19 death rates and are hence complementary to the main findings.

\subsection{Further discussion on empirical results}

We provide further discussions on our empirical findings by drawing comparisons to previous COVID-19 related literature. Firstly, from the preliminary analysis of weak-form market efficiency, our findings on changing efficiency in BRICS currency markets during different sub-periods can be compared to the findings from Narayan (2020) who similarly observes changing weak-form market efficiency in advanced currency markets during the pandemic. Secondly, from our wavelet coherence analysis, we find that COVID-19 statistics can be used to predict currency BRICS currency returns which are similar to that found in Iyke (2020). However, in differing from Iyke (2020), who finds predictability in cycles of $1-5$ days for BRICS countries our study further shows that such high-frequency predictability is shortlived and across a longer sample and most short-run or high-frequency forecastable using COVID-19 statistics disappears after government intervention in markets and markets become forecastable only at lower frequency oscillations. Thirdly, in differing from Li et al. (2021) who find a negative long-run and short-run relationships between COVID-19 death statistics and Chinese currency returns, our findings indicate that COVID-19 death (recovery) statistics have a positive (negative) co-movement with BRICS currency returns and negative (positive) co-movements are found for Chinese markets only at low-frequency oscillations. Fourthly, in line with Rouatbi et al. (2021), our findings indicate that market efficiency has improved within BRICS currency markets during the immunization period of the pandemic.

Our findings also have interesting implications for market participants and policymakers. For instance, the wavelet analysis distinguishes between different frequencies components which are important for capturing the heterogeneous behaviour of market participants who base their decisions across different frequency horizons. In practice, speculative or myopic investments would be concerned with information relating to short-window periods or high-frequency oscillations whilst longer-term or safer investors would be interested in information contained in low-frequency co-movements. Our findings show that many speculative opportunities based on COVID-death statistics existed in BRICS currency markets during the early stages of the pandemic (fever and moderation periods) and yet aftermarket intervention by governments worldwide, these speculative opportunities subside as markets become more informationally efficient. Moreover, the recent immunization period has further improved the efficiency of 
currency markets which highlights the importance which health policy has on currency markets. Note that other adverse events such as the capital insurrection and the more recent Kabul airport terrorist attacks have not had any adverse effects on the efficiency of BRICS currency markets.

\section{Conclusions}

Our study has sought to examine market efficiency in BRICS currency exchanges during the COVID-19 pandemic using more recent data spanning between 3rd February 2020 and 31st August 2021. In our preliminary analysis, we use conventional tests of random walks and martingale process to test for weak-form efficiency in BRICS currency returns. In our main analysis, we use more powerful wavelet coherence tools to model co-movements between public information on COVID-19 health statistics in a time-frequency plane. The findings from both the preliminary and the main analysis provide support for changing market efficiency in BRICS currency markets during the pandemic with market efficiency being most enhanced during the immunization period. These findings remain robust to alternative measures of the COVID-19 health statistics.

Overall, our study has important implications for academics, market participants, and policymakers. Firstly, from an academic standpoint, our study knits together 'bits and pieces' of conflicting evidence on the BRICS currency efficiency during the pandemic. Our study shows that the short-run predictability observed by earlier studies was only short lived and government intervention in financial markets, as well as the recent rollouts of vaccination programmes worldwide, has made the currency markets more efficient over time. However, in contradiction to the strict form of the EMH, we find that BRICS currency returns are partially efficient which is in line with the AMH. Secondly, from the perspective of market participants, our study demonstrates that currency markets are vulnerable to speculative behaviour periods panic particularly during the 'fever period' of the pandemic and during these periods the market was showed signs resembling a 'Black Swan' event. Lastly, our study demonstrates that global health outcomes are at least a necessary condition for improving currency market efficiency and stability in BRICS economics. As more data becomes available future studies should focus on monitoring the evolving nature of efficiency in currency markets and identify newer events which enhance or deteriorate market efficiency.

\section{Declarations}

Conflict of interest The authors declare that they do not have any conflict of interest.

\section{References}

Aguiar-Conraria L. and Soares M. (2010), “The continuous wavelet transform: A primer”, NIPE Working Paper No. 23, August.

Aguiar-Conraria L, Soares M (2014) The continuous wavelet transform: Moving beyond uni- and bivariate analysis. J Econ Surveys 28(2):344-375 
Al-Khazali O, Pyun C, Kim D (2011) Are exchange rate movements predictable in Asia-Pacific markets? Evidence of random walk and martingale difference process. Int Rev Econ Financ 21(1):221-231

Aslam F, Aziz S, Nguyen D, Mughal K, Khan M (2020) On the efficiency of foreign exchange markets in times of the COVID-19 pandemic. Technol Forecasting Social Change 161:e120261

Aumeboonsuke V, Dryver A (2014) The importance of using a test of weak-form market efficiency that does not require investigating the data first. Int Rev Econ Financ 33:3C50-357

Beirne J., Renzhi N., Sugandi E. and Volz U. (2020), "Financial market and capital flow dynamics during the COVID-19 pandemic", ADBI Working Paper No. 1158, June.

Charles A, Darne O, Kim J (2012) Exchange -rate return predictability and the adaptive market hypothesis: Evidence from major foreign exchange rates. J Int Money Finan 31(6):1607-1626

Choi I (1999) Testing the random walk hypothesis for real exchange rates. J Appl Econ 14(3):293-308

Cornell B, Dietrich K (1978) The efficiency of the market for foreign exchange under floating exchange rates. Rev Econ Stat 60(1):111-120

Fama E (1970) Efficient capital markets: A review of theory and empirical work. J Financ 25(2):383-417

Feng G, Yang H, Gong Q, Chang C (2021) What is the exchange rate volatility response to COVID-19 and government interventions? Econ Anal Policy 69:705-719

Frezza M, Bianchi S, Pianese A (2021) Fractural analysis of market (in)efficiency during the COVID-19 pandemic. Finance Res Lett 28:101851

Goodell J (2020) COVID-19 and finance: Agendas for future research. Finance Res Lett 25:e101512

Goodell J, Goutte S (2021) Co-movement of COVID-19 and Bitcoin: Evidence from wavelet coherence analysis. Res Finance Lett 38:101625

Grossman S, Stiglitz J (1980) On the impossibility of informationally efficient markets. America Econ Rev 70(3):393-408

Gunay S (2021) Comparing COVID-19 with the GFC: A shockwave analysis of currency markets. Res Int Business Finan 56:e101377

Han C, Wang Y, Xu Y (2020) Nonlinearity and efficiency dynamics of foreign exchange markets: Evidence from multifractality and volatility of major exchanges. Econ Res Ekonomska Istrazivanja 33(1):731-751

Iyke B (2020) The disease outbreak channel of exchange rate return predictability: Evidence from COVID-19. Emerg Mark Financ Trade 56(10):2277-2297

Jefferson M (2020) A crude future? COVID-19s challenges for oil demand, supply and prices. Energy Res Social Sci 68:e101669

Katusiime L, Shamsuddin A, Agbola F (2017) Foreign exchange market efficiency and profitability of trading rules: Evidence from a developing country. Int Rev Econ Financ 35:315-332

Kim J (2009) Automatic variance ratio test under conditional heteroscedasticity. Econ Lett 92(1):38-43

Li C, Su Z-W, Yaqoob T, Sajid Y (2021) COVID-19 and currency market: A comparative analysis of exchange rate movement in China and USA during the pandemic. Econ Res Ekonomska Istrazivanja. https://doi.org/10.1080/1331677X.2021.1959368

Lo A (2004) The adaptive markets hypothesis: Market efficiency from an evolutionary perspective. J Portfolio Manag 30(5):15-29

Lo A, MacKinlay C (1988) Stock market prices do not follow random walks: Evidence from a simple specification test. Rev Financial Stud 1(1):41-66

Malkiel B (2003) The efficient market hypothesis and its critics. J Econ Perspectives 17(1):59-82

Mnif.,Jarboui A and Mouakhar K, (2020) How the cryptocurrency market has performed during COVID 19? A multifractal analysis. Finan Res Lett 36:101647

Naeem M, Bouri E, Peng Z, Shahzad S, Vo X (2021) Asymmetric efficiency of cryptocurrencies during COVID-19. Physica A: Statistical Mechan Appl 565:125562

Narayan P (2020) Has COVID-19 changed the exchange rate resistance to shocks? Asian Econ Lett 1(1): $1-4$

Narayan P, Devpura N, Wang H (2020) Japanese currency and stock market - What happened during the COVID-19 pandemic. Econ Anal Policy 68:191-198

Narayan P, Phan D, Liu G (2021) COVID-19 lockdowns, stimulus packages, travel bans, and stock returns. Finance Res Lett 38:e101732

Neely C, Weller P, Ulrich J (2009) The adaptive markets hypothesis: Evidence from the Foreign exchange market. J Financ Quant Anal 44(2):467-488

Okorie D, Lin B (2021) Adaptive market hypothesis: The story of the stock market and COVID-19 pandemic. North Am J Econ Finance 57:101397 
Ozkan O (2021) Impact of COVID-19 on stock market efficiency: Evidence from developed countries. Res Int Business Finan 58:e101445

Park C, Irwin S (2007) What do we know about the profitability of technical analysis. J Econ Sur 21(4):786-826

Pazarbasioglu C, Otker I (1997) Likelihood versus timing of speculative attacks: A case study of Mexico. Eur Econ Rev 41(3-5):837-845

Rouatbi W, Demir E, Kizys R, Zaremba A (2021) Immunizing markets against the pandemic: COVID-19 vaccinations and stock volatility around the world. Int Rev Finan Anal 77:e101819

Shiller R (2003) From efficient markets theory to behavioural finance. J Econ Persp 17(1):83-104

Shiller R. (2014), "Speculative asset prices (Nobel Prize Lecture)", Cowles Foundation Discussion Paper No. 1936.

Torrence and Compo (1998) A practical guide to wavelet analysis. Bull Am Meteorol Soc 79(1):61-78

Umar Z, Gubareva M (2020) A time-frequency analysis of the impact of the COVID-19 induced pandemic on the volatility of currency and cryptocurrencies. J Behavioural Experimental Finan 28:e100404

Vasileiou E (2021) Behavioural finance and market efficiency in the time of the COVID-19 pandemic. Int Rev Appl Econ 35(2):224-241

Vasileiou E, Samitas A, Karagiannaki M, Dandu J (2021) Health risk and the efficient market hypothesis in the time of COVID-19. Int Rev Appl Econ 35(2):210-223

Wang J, Wang X (2021) COVID-19 and financial market efficiency: Evidence from an entropy-based analysis. Finan Res Lett 42:101888

Xu Y, Lien D (2021) COVID-19 and currency dependencies: Empirical evidence from BRICS. Finance Res Lett. https://doi.org/10.1016/j.frl.2021.102119

Yang Y, Shao Y, Shao H, Stanley E (2019) Revisiting the weak-form efficiency of the EUR/CHF exchange rate market: Evidence from episodes of different Swiss franc regimes. Physica A 523:734-746

Publisher's Note Springer Nature remains neutral with regard to jurisdictional claims in published maps and institutional affiliations. 